From the Department of Physiology, Veterinärhögskolan, Stockholm, Sweden and the Department of Zoology, University of Michigan, Ann Arbor, Michigan, U.S.A.

\title{
Reformation of Taste Buds by Crossed Sensory Nerves in the Rat's Tongue
}

By

Bruce OAKLey

Received 20 August 1969

Abstract

OAKLeY, B. Reformation of taste buds by crossed sensory nerves in the rat's tongue. Acta physiol. scand. 1970. 79. 88-94.

Rat taste buds degenerate and disappear when their nerve supply is cut. Regeneration of the taste nerve fibres causes certain epithelial cells to differentiate into slender receptor cells comprising the taste bud. In this study by cross-union the glossopharyngeal (IXth) nerve was made to innervate the front of the tongue, and in other rats the chorda tympani nerve was forced to grow to the back of the tongue. 'These cross-regenerated sensory nerves were able to cause differentiation of epithelial cells into taste buds, whose number and distribution were histologically determined 15 weeks postoperatively. The cross-innervating IXth nerve reestablished taste buds in the existing fungiform papillae in conformity with the normal number and distribution of taste buds at the front of the tongue. The chorda tympani, forced to innervate the back of the tongue, reestablish in the foliae papillae more than 1.5 times as many taste buds as it normally innervates. The number of taste buds normally innervated by the chorda tympani must, therefore, be restricted by the capacity of the anterior tongue tissue to respond to this nerve's influence. This study indicates that the distribution and total number of taste buds in the rat tongue is limited by the inherent nature of the tongue region being innervated (tissue-specific) rather than by the type of nerve supplying the taste buds (nervespecific).

Taste buds on the rat's tongue are located in three different types of papillae. The fungiform papillae are punctate spots $0.3 \mathrm{~mm}$ in diameter, which are distributed over the dorsal surface of the anterior two thirds of the tongue. They are especially numerous near the tip of the tongue. Each of the approximately 90 fungiform papillae found on each side of the tongue, contains, with rare exceptions, only one taste bud. All of the fungiform taste buds are innervated by the chorda tympani nerve (Fish, Malone and Richter 1944, Whiteside 1927). On the posterior tongue there is a single midline circumvallate papilla with several hundred taste buds embedded in both the inner and outer walls of the nearly circular trench or furrow surrounding the papilla. About $90 \%$ of these taste buds receive bilateral innervation from both IXth nerves (Guth 1963, Whiteside 1927). The third kind of papillae that have taste buds are the foliate papillae on each side of the posterior tongue. These 
are a series of $5-8$ closely spaced furrows within which numerous taste buds are embedded.

When a taste bud is deprived of its normal nerve supply the taste bud degenerates in 1-2 weeks (Vintschgau 1880, Whiteside 1927, Zelena 1964). If the nerve is able to regenerate, it will initiate the formation of a new taste bud from the surrounding epithelial cells. Oakley (1967) has previously shown that the IXth nerve can be made to innervate the anterior portion of the rat tongue and the chorda tympani the posterior portion of the tongue. Such cross-innervation results in a changed responsiveness of the nerve to taste stimulation of the tongue, as measured by summated action potential discharges from the whole nerve. That it, the taste responses are characteristic of the tissue innervated (tissue-specific) and not of the nerve which happens to innervate the region (nerve-specific). On this basis one might also expect in the cross-innervated rat tongue that the distribution and number of taste buds would be tissue-specific and hence independent of the kind of innervating nerve (chorda tympani or IXth nerve). It was the purpose of this investigation to observe histologically the number and distribution of tongue taste buds reformed under the influence of cross-innervation by either the chorda tympani or IXth nerve.

\section{Methods}

Twelve female Sprague-Dawley albino rats having either regenerated or cross-regenerated taste nerves were used in this experiment. The animals were anesthetized with urethane-pentobarbital or nembutal, and unilateral end-to-end sensory nerve anastomoses were performed. In two controls the chorda tympani nerve was cut unilaterally and the central portion of the chorda rejoined to the peripheral portion. In two other control animals the chorda was cut and the lingual nerve cut central to the branching out of the chorda; then the central portion of the chorda was joined to the peripheral portion of the lingual nerve. As experimental animals, four rats with cross-regenerated IXth nerves were utilized in which the central portion of the IXth nerve was sutured to the peripheral part of the chorda tympani. Four cross-regenerated chorda tympani rats were also used in which the central part of the chorda was sutured to the peripheral part of the IXth nerve. In all operations the degenerating peripheral nerve stump served simply as a guide for the regenerating fibers. All operations were unilateral. Some of the electrophysiological properties of the cross-regenerated nerves have been reported and further methodological details may be found in that paper (Oakley 1967). After an average of fifteen postoperative weeks the tongues were fixed in $10 \%$ formalin and embedded in paraffin. Complete $10 \mu$ serial, horizontal sections of the foliate and circumvallate papillae were mounted on slides and stained with Heidenhain's iron hematoxylin. This stain leaves a small dark spot around the taste pore which facilitates the task of counting numerous taste buds in serial sections (Guth 1963). In the experimental and operated control rats the first 50 sections at the tip were discarded and the next 325 serial sections of the front of the tongue were examined for taste buds. In three additional rats the entire anterior part of the tongue was serially sectioned $(1200,10 \mu$ sections, for each rat). In two of these rats the entire posterior part of the tongue was also examined (700, $10 \mu$ sections, for each rat), 3 weeks after transection of the IXth nerves.

\section{Results}

102, 83 and 95 taste buds (Mean =93) were counted unilaterally in the 3 rats whose entire anterior tongue was serially sectioned. In these and in all other rats examined all taste buds on the anterior portion of the tongue occurred without exception in the fungiform papillae. In over $98 \%$ of the fungiform papillae there was only one taste 


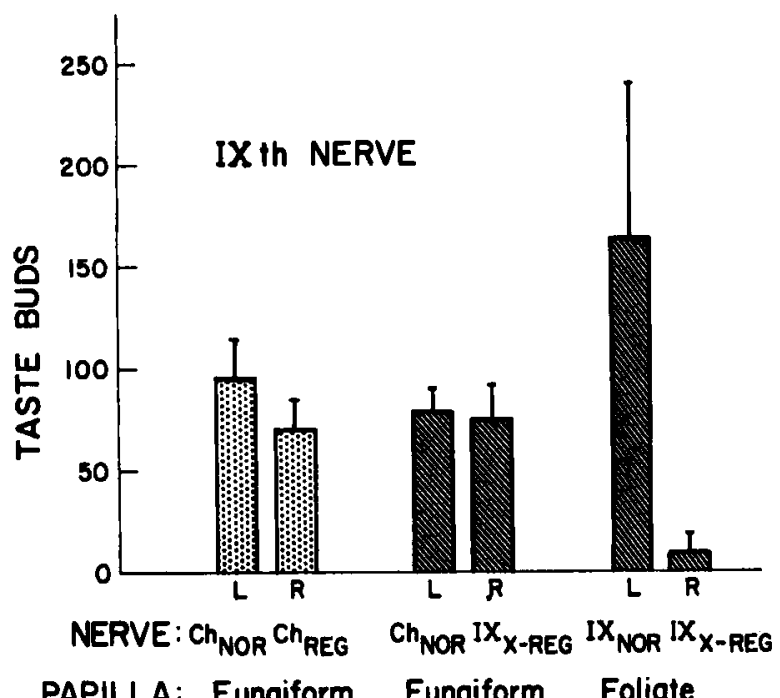

PAPILLA: Fungiform Fungiform Foliate
Fig. 1. The number of taste buds innervated by the control regenerated chorda tympani and cross-regenerated IXth nerves. Each rat served as its own control. Thus, for each of the three pairs of bars the left (L) or normal side of the tongue is compared with the right (R) or experimental side. Each bar is the mean of four values; dotted $=$ control rats, cross-hatched $=$ experimental rats. One standard deviation is shown. The legend at the bottom indicates the type of innervating nerve (normal, regenerated or cross-regenerated) and the location of the taste buds. The counts for the fungiform taste buds were multiplied by 2.1 to obtain the total number of fungiform taste buds.

bud per papilla; double taste buds or the complete absence of a taste bud in a fungiform papilla occurred less than $2 \%$ of the time. The only taste buds found in serial sections of the entire posterior tongue after bilateral IXth nerve section in two of the above rats were located in the foliate papillae. Counts of foliate taste buds in six additional rats after IXth nerve section gave a mean of 16 foliate taste buds, unilaterally $(\mathbf{N}=8, \mathrm{SD}=7)$. (This is in agreement with Whiteside (1927) who has shown that the chorda tympani nerve innervated a few taste buds in the foliate papillae.) Thus, the taste buds normally innervated by the chorda tympani nerve comprise an average of 93 fungiform taste buds and 16 foliate taste buds for an average total of 109 taste buds. To eliminate both the time consuming examination of the entire anterior part of the tongue and the difficulty of counting taste buds at the extreme tip of the tongue, a sampling procedure was developed. From the counts of taste buds on the entire anterior part of the tongue in 3 rats and from counts on at least $0.5 \mathrm{~cm}$ of seven additional anterior tongues it was found that the number of fungiform taste buds could be reliably determined by examining the front of the tongue. $47 \% \pm 15 \%$ of the fungiform taste buds are contained within a $3.25 \mathrm{~mm}$ block of tongue tissue 0.5 to $3.75 \mathrm{~mm}$ from the tip of the tongue. (Counts of taste buds on the two sides agreed within $10 \%$ which was also the same as the left-right variation in counts of fungiform taste buds for the total anterior tongue.) Thus, in the experimental and operated control rats the status of fungiform taste buds was determined by directly counting all taste buds in this $3.25 \mathrm{~mm}$ block of tissue at the front of the tongue.

All control regenerated and cross-regenerated taste nerves reformed taste buds and these were located in the taste papillae characteristic of the tongue region invaded by the nerve. The ability of control regenerated chorda tympani nerve fibres 
Fig. 2. The spatial distribution of fungiform taste buds innervated by normal and crossregenerated nerves. Each data point is the mean of four animals and is placed at the mid-point of its $400 \mu$ sample of tongue tissue, with sampling beginning $0.5 \mathrm{~mm}$ from the tip of the tongue. The data for the papillae only (denervated and therefore lacking taste buds), comes from the 4 experimental animals having cross-regenerated chorda tympani nerves which innervated the posterior tongue region.

Ordinate: number of taste buds. Abscissa: mm.

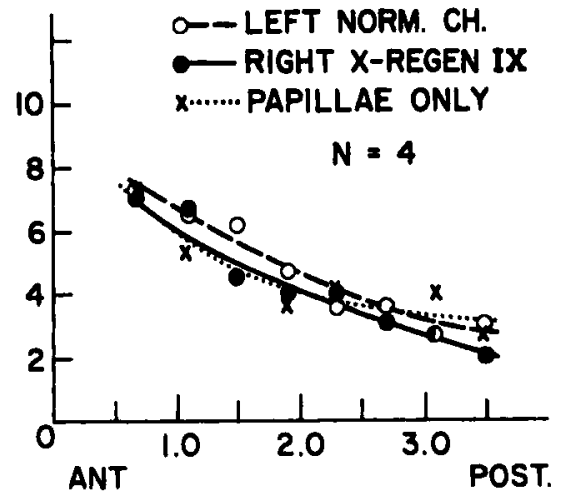

to reestablish fungiform taste buds is shown by the left pair of bars in Fig. 1. The normal number of fungiform taste buds on the left side of the tongue is compared with the number of fungiform taste buds reformed on the right side by the regenerated chorda tympani nerve. (It made no difference whether the chorda tympani had been sutured to itself for regeneration or whether it had been sutured to the peripheral stump of the lingual nerve.)

In 4 experimental rats the cross-regenerated IXth nerve successfully reformed single taste buds in the fungiform papillae (center pair of bars in Fig. 1). The pair of bars on the right in Fig. 1 indicates that very few taste buds remain in the right foliate papillae when the IXth nerve is forced to the front of the tongue. One may therefore conclude that the right foliate papillae, which were initially denervated by the nerve crossing operation, were not quantitatively resupplied by the IXth nerve growing back from the anterior part of the tongue. Since only the left IXth nerve remained to innervate the posterior part of the tongue it was also possible to count the total number of taste buds normally innervated by one IXth nerve in the circumvallate and foliate papillae (Mean $=647 \pm$ S.D. 135). The failure to observe an abnormally large number of taste buds on the front of the right side of the tongue could have been due in whole or part to inadequate cross-regeneration of the taste fibres within the IXth nerve. However, cross-innervation by the IXth nerve seemed to be no less effective than control reinnervation by the chorda tympani in that in both cases 8-10\% of the fungiform papillae lacked taste buds. (In normal rats less than $1 \%$ of the fungiform papillae lack taste buds.) As shown in Fig. 2 the spatial distribution of cross-innervated fungiform papillae at the front of the tongue on the right is indistinguishable from the normal distribution of fungiform taste buds on the left side of the tongue. A similar spatial distribution of denervated fungiform papillae without taste buds was found, as determined by examining the front of the tongue of the four rats with a cross-regenerated chorda tympani nerve. Thus, there was no evidence from an examination of the front of the tongue that the taste buds inner- 


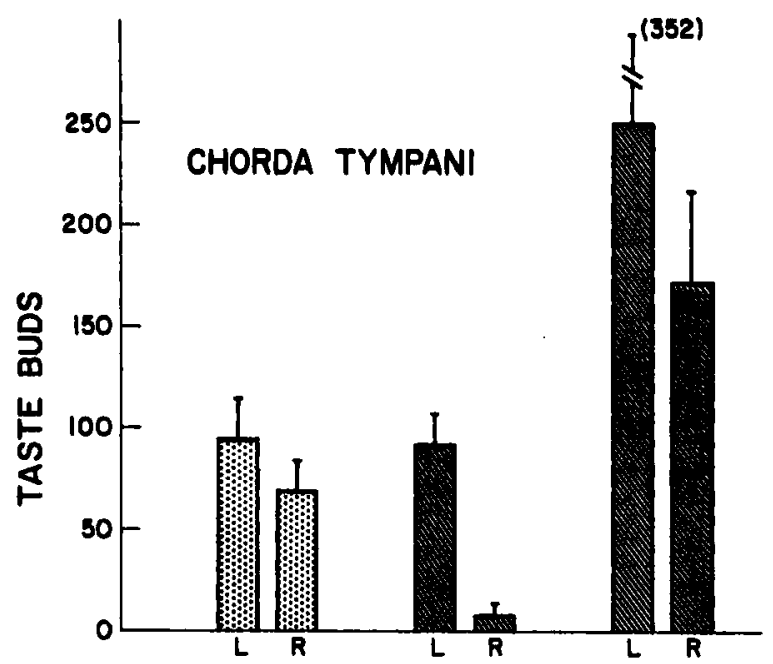

NERVE: $\mathrm{Ch}_{\text {NOR }} \mathrm{Ch}_{\text {REG }} \quad \mathrm{Ch}_{\text {NOR }} \mathrm{Ch}_{X-R E G}{ } \mathrm{IX}_{\text {NOR }} \mathrm{Ch}$ X-REG PAPILLA: Fungiform Fungiform Foliate
Fig. 3. The number of taste buds innervated by the control, regenerated and cross-regenerated chorda tympani nerves. Axes and the left pair of bars as in Fig. 1.

vated by the cross-regenerated IXth nerve were abnormal in their relationship to fungiform papillae, abundance or spatial distribution.

When the chorda tympani is forced to innervate the posterior tongue area most taste buds permanently disappear from the fungiform papillae and numerous taste buds are reformed in the foliate papillae. The average number of foliate taste buds innervated by the cross-regenerated chorda tympani nerve was almost twice the number of fungiform taste buds innervated by the chorda tympani on the normal side of the tongue (Fig. 3, center and right pair of bars). The number of foliate taste buds innervated by the cross-regenerated chorda tympani nerve of these four experimental rats was significantly greater than the total number of taste buds (fungiform and foliate) normally innervated by the chorda tympani nerve as determined by serial sectioning of the entire tongue of three control rats $(p=0.028$, Mann-Whitney $U$ test).

The number of furrows in the foliate papillae varied from $5-7$ in the 4 experimental rats with a cross-regenerated chorda tympani nerve. The distribution of taste buds in these furrows is presented in Fig. 4. There is no tendency apparent for the cross-innervated taste buds to predominate in one furrow; they appear to be distributed throughout all furrows in the normal fashion.

\section{Discussion}

The basic result of this study is that cross-regenerated tongue sensory nerves can reform taste buds, and their number and distribution closely approximates the normal situation for the particular tongue region. That is, the location and density of taste 
Fig. 4. Average number of taste buds for 4 rats occurring in 6 foliate papillae. The most anterior furrow on each side was defined as 1 , and the more posterior furrows were then numbered consecutively. (Only two rats had the 6th papilla. Ten taste buds in a 7 th papilla of one rat are not shown.) One standard deviation is plotted.

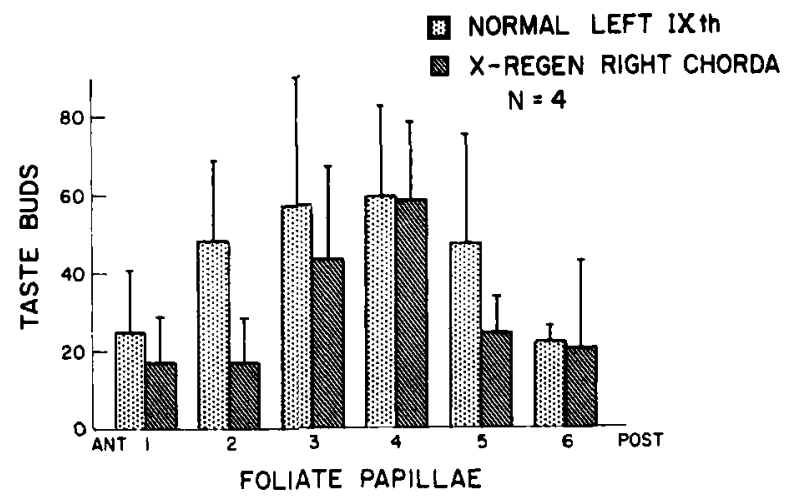

buds is tissue-specific. This means that the chorda tympani nerve, for example, which normally innervates an average total of 109 taste buds, will, if directed to a favorable region (the posterior tongue), form more than one and one half times as many taste buds. Accordingly, the limiting factor in the number of taste buds normally innervated by the chorda tympani nerve is the capacity of the anterior tongue tissue to respond to its influences.

Because the circumvallate papillae receives innervation from both IXth nerves, about $90 \%$ of its buds should have survived the nerve crossing operations (Guth 1963, Whiteside 1927). It is likely that the cross-regenerated chorda tympani nerve innervated some of the circumvallate taste buds (with or without mutual innervation by the intact IXth nerve), but this can only be determined quantitatively in experiments which also cut the remaining IXth nerve. In the present experiment there was no significant difference between the number of taste buds in normal circumvallate papillae and the number in the circumvallate papillae of the four experimental rats with a cross-regenerated chorda tympani nerve. Previous electrophysiological investigation indicated that cross-regenerated chorda tympani fibres extended to the circumvallate papilla region (Oakley 1967).

In the normal rat the chorda tympani nerve innervates an average of 16 foliate taste buds and all of these are in the anterior folds. Why doesn't it normally innervate more, since in cross-regeneration it is perfectly capable of forming taste buds in all of the foliate papillae? It is tempting to point to the example of vertebrate skeletal muscle where the initial innervation of a muscle fibre usually excludes further nervous innervation (Harrisson 1910). Thus, the IXth nerve fibres may arrive first in development and/or successfully dominate in competition with the chorda tympani endings. However, since multiple innervation is known to exist in the sense of taste, $(90 \%$ of the taste buds in the circumvallate papilla are bilaterally innervated (Guth 1963, Whiteside 1927)) it is more likely that the chorda tympani normally sends only a few fibres to the region of the foliate papillae, and these fibres simply lack the capacity to form or innervate a large number of taste buds. 
There are three major conclusions of this study:

1. Taste buds can be reformed by cross-innervation of the tongue with the IXth or chorda tympani nerves.

2. Both the distribution and number of such cross-innervated taste buds are characteristic of the tongue region being innervated (tissue-specific).

3. When placed in a favorable tissue environment (i.e., the posterior part of the tongue) the chorda tympani is capable of initiating the formation of more than one and one half times as many taste buds as it normally innervates.

I thank Prof. Y. Zotterman for making facilities available for this work. Supported in part by U.S.P.H.S. Grant NB-07072.

\section{References}

Fisin, H. S., P. D. Malone, and C. P. Righter, The anatomy of the tongue of the domestic Norway rat. I: The skin of the tongue; the various papillae, their number and distribution. Anat. Rec. 1944. 89. 429-440.

GuTu, L., Histological changes following partial denervation of the circumvallate papilla of the rat. Exp. Neurol. 1963. 8. 336-349.

Harrisson, R. G.. The outgrowth of the nerve fiber as a mode of protoplasmic movement. J. Exp. Zool. 1910. 9. 787--846.

OAKLEY, B., Altered temperature and taste responses from cross-regenerated sensory nerves in the rat's tongue. J. Physiol. (Lond.) 1967. 188. 353-371.

Vintscirgau, M. von., Beobachtungen über die Veränderungen der Schmeckbecher nach Durchschneidung des n. Glossopharyngeus. Pflügers Arch. ges. Physiol. 1880. 23. 1-13.

WiItesine, B., Nerve overlap in the gustatory apparatus of the rat. J. comp. Neurol. 1927. 44. $363-377$.

Zelens, J., Development, degeneration and regeneration of receptor organs. In Progress in Brain Research: 13 Mechanisms of Neural Regeneration, pp. 175-213. Ed. by M. Singer and J. P. Schade. Elsevier, Amsterdam. 1964. 